\title{
CONF-950412-38
}

NOTE: This is a preprint of a paper being submitted for publication. Contents of this paper should not be quoted or referred to without permission of the author(s).

To be submitted to 1995 MRS Spring Meeting, Material Research Society Symposium Proceedings, Symposium Q: Film Synthesis and Growth Using Energetic Beams, April 17-21, 1995, San Francisco, CA

\section{VAPOR BREAKDOWN DURING ABLATION BY NANOSECOND LASER PULSES}

C. L. Liu, J. N. Leboeuf, R. F. Wood, D. B. Geohegan, J. M. Donato, K. R. Chen, and A. A. Puretzky

\author{
SOLID STATE DIVISION \\ OAK RIDGE NATIONAL LABORATORY \\ Managed by \\ MARTIN MARIETTA ENERGY SYSTEMS, INC. \\ Under \\ Contract No. DE-AC05-84OR21400 \\ With the \\ U. S. DEPARTMENT OF ENERGY \\ OAK RIDGE, TENNESSEE
}

April 1995 


\section{DISCLAIMER}

Portions of this document may be illegible in electronic image products. Images are produced from the best available original document. 


\title{
VAPOR BREAKDOWN DURING ABLATION BY NANOSECOND LASER PULSES
}

\author{
C. L. Liu, J. N. Leboeuf,* R. F. Wood, D. B. Geohegan, \\ J. M. Donato, ${ }^{* *}$ K. R. Chen,* and A. A. Puretzky \\ Solid State Division, Oak Ridge National Laboratory \\ Oak Ridge, TN 37831-6032
}

\author{
*Fusion Energy Division, ORNL \\ **Engineering Physics and Mathematics Division, ORNL
}

\begin{abstract}
Plasma generation through vapor breakdown during ablation of a $\mathrm{Si}$ target by nanosecond $\mathrm{KrF}$ laser pulses is modeled using 0-dimensional rate equations. Although there is some previous work on vapor breakdown by microsecond laser pulses, there have been no attempts made on vapor breakdown by nanosecond laser pulses. This work intends to fill the gap. A kinetic model is developed considering following factors: (1) two temperatures of both electrons and heavy-body particles (ions, neutrals, and excited states of neutrals), (2) absorption mechanisms of laser energy include inverse bremstrahlung (IB) processes and photoionization of excited states, (3) ionization acceleration mechanisms included are electron-impact excitation of ground state neutrals, electron-impact ionization of exited states of neutrals, photoionization of excited states of neutrals, and all necessary reverse processes. The rates of various processes considered are calculated according to the formula given by Zel'dovich and Raizer [1]. We use a second order predictor-corrector numerical scheme for iterations of the rate equations. The rate equations are solved for five quantities, namely, densities of electrons, neutrals, and excited states of neutrals, and the temperatures of electrons and heavy-body particles. The total breakdown times (sum of evaporation time and vapor breakdown time) at different energy fluences are then calculated. The results are compared with experimental observations of Si target ablation using a $\mathrm{KrF}$ laser. A more detailed description of the model and the results will be published later [2].
\end{abstract}

\section{Introduction}

One of the main techniques for laser materials processing is pulsed laser deposition (PLD) of thin films. The advantages of PLD compared to other techniques include, novel epitaxial and low temperature growth of homogeneous and heterogeneous films by utilizing energetic species, stoichiometric ablation of constituent species of the target, and growth of metastable phases layer-by-layer under nonequilibrium ablation conditions. While experimentalists are trying to find optimal conditions for thin film growth by PLD, a systematic effort in modeling of various physical processes during deposition is needed. For computational modeling of the complicated processes such as occur during PLD, one faces the challenge not only to better understand the fundamentals of the processes, but also to utilize the most appropriate computational techniques in the modeling. Modeling of vapor breakdown due to the interactions between vapor and incoming laser beam during ablation is such a challenge. Understanding this phenomenon is extremely important in assessing the final state of the plume after the pulse and subsequent plume expansion and transport toward the substrate. There have been no pervious attempts made to model vapor breakdown under irradiation of nanosecond laser pulses, although some work was done for microsecond laser pulses [3]. In this paper, we present preliminary results from theoretical modeling of vapor breakdown leading to plasma generation (fully ionized gas) through the interactions between the evaporated gas (plume) and the incoming laser beam during ablation, in an effort to fill the gap and to pursue systematic theoretical study on all the physical processes of laser ablation. 


\section{Theory for Vapor Breakdown}

\subsection{Physical model for vapor breakdown}

A reasonable physical model can be set up for the early period of the ablation. During the initial ablation, generated vapor experiences a slow 1-D expansion and the expanding velocity can be taken as a constant $\left(V_{o}\right)$. The vapor can be assumed to be homogeneous during this early stage of the ablation. In the vapor, ions, electrons, excited states of neutrals, and ground states of neutrals all exist. Evaporation continues to supply these particles $\left(\left(\mathrm{N}_{\mathrm{e}}\right)_{\mathrm{o}}\right.$, $\left.\left(\mathrm{N}_{\mathrm{o}}\right)_{0},\left(\mathrm{~N}^{*}\right)_{0}\right)$ into the vapor during ablation and thus contributes to the total energy in the vapor. At the mean time, electrons in the vapor absorb energies from photons in the laser beam and exchange the energies with heavy-body particles through elastic collisions, therefore two temperatures, i.e., electron temperature $\left(T_{e}\right)$ and heavy-body particle temperature $\left(T_{h}\right)$, are necessary. Some neutrals can be ionized via excited states either by electron-impact or photoionization. A schematic of this physical model is shown in Fig.1 along with a $\mathrm{KrF}$ laser pulse used in our model.

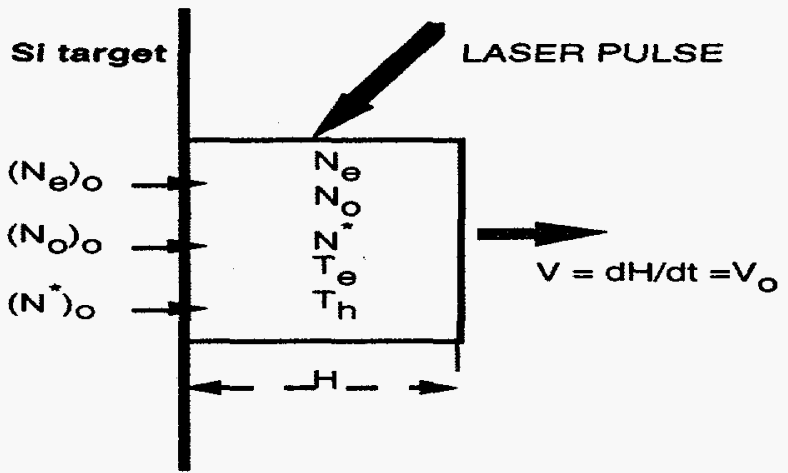

(a)

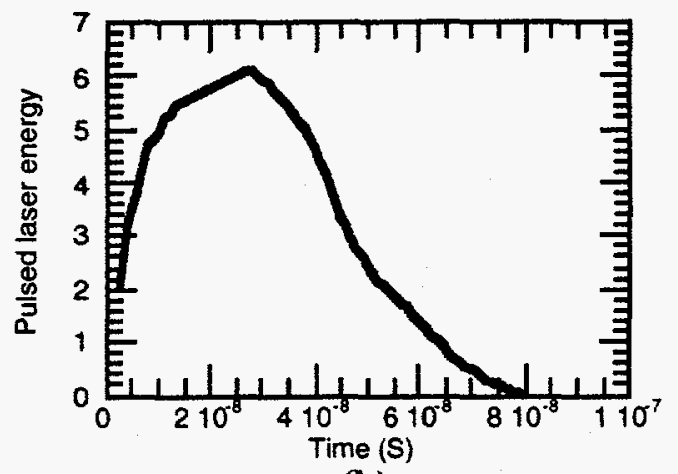

(b)

Fig. 1 (a) Schematic of the physical model used for modeling of vapor breakdown (b) laser pulse used in the modeling calculations.

\subsection{Mechanisms of laser energy absorption}

Two absorption mechanisms of laser energy are considered in our model. One is the inverse bremsstrahlung absorption through electron-atom and electron-ion interactions. The absorption coefficients for electron-atom IB, $\alpha_{e-a}$, and electron-ion IB, $\alpha_{e-i}$, are given by [4]

$$
\begin{aligned}
& \alpha_{\mathrm{e}-\mathrm{a}}=2.90 \times 10^{19} \mathrm{~N}_{\mathrm{e}} \mathrm{N}_{\mathrm{o}} \mathrm{T}_{\mathrm{e}}^{1.5} \mathrm{G}_{\mathrm{e}-\mathrm{a}} / \mathrm{v}^{3} \\
& \alpha_{\mathrm{e}-\mathrm{i}}=3.42756 \times 10^{6} \mathrm{~N}_{\mathrm{e}}^{2} \mathrm{G}_{\mathrm{e}-\mathrm{i}} /\left(\left(\mathrm{T}_{\mathrm{h}}\right)^{1 / 2} \mathrm{v}^{3}\right)
\end{aligned}
$$

where $N_{e}$ and $N_{0}$ are electron and neutral densities, $T_{e}$ and $T_{h}$ (in $K$ ) are the electron and heavy-body temperatures, $\mathrm{G}_{\mathrm{e}-\mathrm{a}}$ and $\mathrm{G}_{\mathrm{e}-\mathrm{i}}$ are the Gaunt factors for electron-atom $\mathrm{IB}$ and electron-ion IB, and $v$ is the frequency of laser pulse. Another absorption mechanism considered is photoionization of an excited state. The cross section $\sigma$ is given by [1]

$$
\sigma=7.9 \times 10^{-18}\left(\frac{\mathrm{E}_{\mathrm{ion}}}{\mathrm{hV}}\right)^{3}\left(\frac{\mathrm{I}_{\mathrm{H}}}{\mathrm{E}_{\mathrm{ion}}}\right)^{1 / 2}
$$


where $E_{i o n}$ (in $\mathrm{eV}$ ) is the ionization energy of the excited state, hv is the photon energy of laser pulse, and $I_{H}$ (in eV) is the hydrogen ionization potential. The total energy absorbed $\left(I_{a b}\right)$ by the two mechanisms from laser energy $(I)$, is then

$$
I_{a b}=\left(\alpha_{e-a}+\alpha_{e-i}+\sigma N^{*}\right) I
$$

\subsection{Kinetic theory for breakdown}

There are two necessary conditions for vapor breakdown, i.e., one is "priming" electrons and another is electron density acceleration mechanism. One can consider the electron density as an indicator of the ionization level in the plume since it is directly proportional to the ion density in the plume. In our case, the electron density is equal to the ion density since only singly charged particles of Si are considered. There are many sources for "priming" electrons, such as local thermal ionization described by Saha equation, thermionic emission from the target surface and from heated liquid droplets in the plume, shock heating and ionization, surface defects which are thermally uncoupled with the bulk, avalanche and photoionization within the solid target near the surface, etc. Once the "priming" electrons exist, its acceleration mechanism leading to breakdown becomes important. We consider following forward and reverse processes for electron density acceleration and deceleration, corresponding rates are also given [1]:

(1) Electron-impact excitation of ground state neutrals

$$
\mathrm{Si}+\mathrm{e}+\mathrm{E}_{\mathrm{ex}}=\mathrm{Si}^{*}+\mathrm{e}
$$

Forward rate from ground to excited states, $\mathrm{K}_{\mathrm{g}-\mathrm{e}}$ :

$\mathrm{K}_{\mathrm{g}-\mathrm{e}}=6 . \times 10^{-12}\left(\mathrm{~T}_{\mathrm{e}}\right)^{1 / 2}\left(2 .+\mathrm{E}_{\mathrm{ex}} / \mathrm{k}\right.$
Backward rate from excited to ground states, $\mathrm{K}_{\mathrm{e}-\mathrm{g}}$ :

$$
\mathrm{K}_{\mathrm{g}-\mathrm{e}}=6 . \times 10^{-12}\left(\mathrm{~T}_{\mathrm{e}}\right)^{1 / 2}\left(2 .+\mathrm{E}_{\mathrm{ex}} / \mathrm{kT}_{\mathrm{e}}\right) \mathrm{N}_{\mathrm{e}} \mathrm{N}_{\mathrm{o}}
$$

$$
\mathrm{K}_{\mathrm{e}-\mathrm{g}}=1.8 \times 10^{-10}\left(\mathrm{~T}_{\mathrm{e}}\right)^{1 / 2}\left(2 .+\mathrm{E}_{\mathrm{ex}} / \mathrm{kT}_{\mathrm{e}}\right) \mathrm{N}_{\mathrm{e}} \mathrm{N}^{*}
$$

(2) Electron-impact ionization of excited states of neutrals

$$
\mathrm{Si}^{*}+\mathrm{e}+\mathrm{E}_{\mathrm{ion}}=\mathrm{Si}^{+}+\mathrm{e}+\mathrm{e}
$$

Forward rate from excited to ionic states, $\mathrm{K}_{\mathrm{e}-\mathrm{i}}$ :

$$
\mathrm{K}_{\mathrm{e}-\mathrm{i}}=2.2 \times 10^{-10}\left(\mathrm{~T}_{\mathrm{h}}\right)^{1 / 2}\left(\frac{\mathrm{I}_{\mathrm{H}}}{\mathrm{E}_{\mathrm{ion}}}\right)^{2} \mathrm{~N}_{\mathrm{e}} \mathrm{N}^{*} \exp \left(-\mathrm{E}_{\mathrm{ion}} / \mathrm{kT}_{\mathrm{e}}\right)
$$

Backward rate from excited to ground states, $\mathrm{K}_{\mathrm{i}-\mathrm{e}}$ :

$$
\mathrm{K}_{\mathrm{i}-\mathrm{e}}=1 . \times 10^{-25}\left(\mathrm{~T}_{\mathrm{h}}\right)^{-1}\left(\frac{\mathrm{I}_{\mathrm{H}}}{\mathrm{E}_{\mathrm{ion}}}\right)^{2}\left(\mathrm{~N}_{\mathrm{e}}\right)^{3}
$$

(3) Photoionization of excited states of neutrals

$$
\mathrm{Si}^{*}+\mathrm{hv}=\mathrm{Si}^{+}+\mathrm{e}
$$

where $E_{\text {ex }}$ is the energy required for ground state neutrals to be excited. A schematic of all the kinetic processes considered in the model is shown in Fig. 2.

According to Zel'dovich and Raizer [1], we consider heating of heavy-body particles by hot electrons through elastic collisions. The rate of change in electron temperature, $\tau_{e}$, is

$$
\tau_{\mathrm{e}}=\frac{7 . \times 10^{3}\left(\mathrm{~T}_{\mathrm{e}}\right)^{3 / 2}}{(\ln \Lambda)\left(\mathrm{N}_{\mathrm{e}}+(1 / 200 .)\left(\mathrm{N}^{*}+\mathrm{N}_{\mathrm{o}}\right)\right)}
$$


where $\Lambda$ is the plasma parameter, given by $\Lambda=\frac{3 .\left(k T_{h}\right)^{3 / 2}}{2\left(4 \pi T_{h}\right)^{1 / 2} e^{3}\left(N_{e}\right)^{1 / 2}}$.

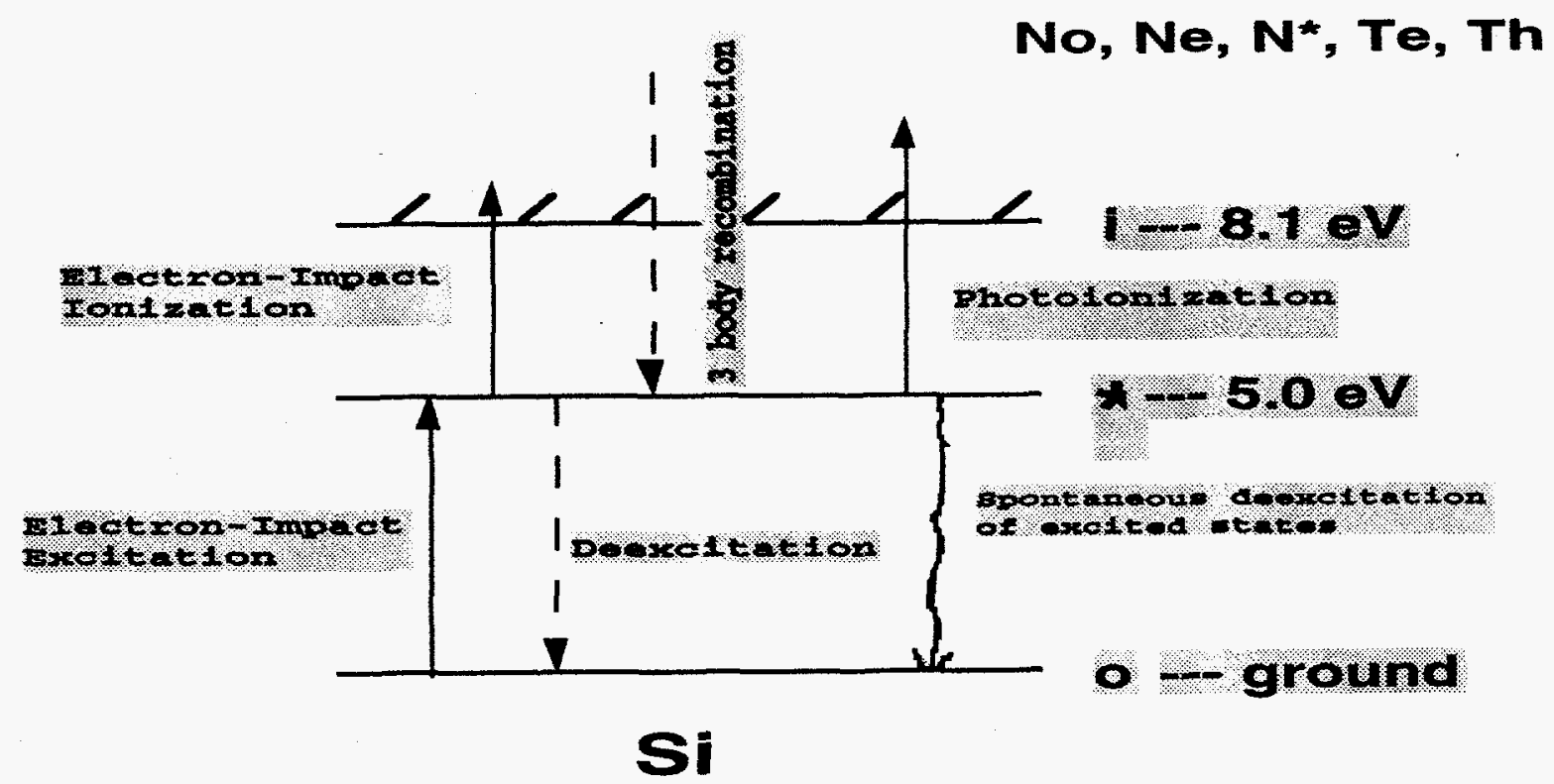

Fig. 2 Schematic of kinetic processes considered in our model.

Similarly for the rate of change in heavy-body temperature, $\tau_{\mathrm{h}}$, is given by

$$
\tau_{h}=\frac{7 . x 10^{3}\left(T_{e}\right)^{3 / 2}}{(\ln \Lambda) N_{e}}
$$

\section{Numerical calculations for vapor breakdown}

From conservation equations, we can write the rate equations for electrons, excited states of neutrals, and ground states of neutrals:

For electrons:

$$
\frac{\mathrm{d}}{\mathrm{dt}}\left[\mathrm{N}_{\mathrm{e}}\right]=-\mathrm{N}_{\mathrm{e}} \frac{1}{\mathrm{H}} \frac{\mathrm{dH}}{\mathrm{dt}}+\left(\mathrm{K}_{\mathrm{e}-\mathrm{i}}-\mathrm{K}_{\mathrm{i}-\mathrm{e}}\right)+\sigma \frac{\mathrm{I}_{\mathrm{ab}}}{\mathrm{hv}} \mathrm{N}^{*}+\frac{\left(\mathrm{N}_{\mathrm{e}}\right)_{0}}{\mathrm{H}}
$$

For excited states of neutrals:

$$
\frac{d}{d t}\left[N^{*}\right]=-N^{*} \frac{1}{H} \frac{d H}{d t}+\left(K_{g-e}-K_{e-g}\right)+\left(K_{i-e}-K_{e-i}\right)-\sigma \frac{I_{a b}}{h v} N^{*}-\frac{N^{*}}{\tau^{*}}+\frac{\left(N^{*}\right)_{0}}{H}
$$

For ground states of neutrals:

$$
\frac{\mathrm{d}}{\mathrm{dt}}\left[\mathrm{N}_{\mathrm{O}}\right]=-\mathrm{N}_{\mathrm{O}} \frac{1}{\mathrm{H}} \frac{\mathrm{dH}}{\mathrm{dt}}+\left(\mathrm{K}_{\mathrm{e}-\mathrm{g}}-\mathrm{K}_{\mathrm{g}-\mathrm{e}}\right)+\frac{\left(\mathrm{N}_{\mathrm{O}}\right)_{\mathrm{O}}}{\mathrm{H}}
$$

where the first terms in eqs. $(10,11,12)$ are due to dilution upon the vapor expansion, the last terms are due to resupply of particles from evaporation, and $\tau^{*}$ is the lifetime of excited states. Constant supply of material $\left(\left(\mathrm{N}_{\mathrm{e}}\right)_{0},\left(\mathrm{~N}_{\mathrm{o}}\right)_{0},\left(\mathrm{~N}^{*}\right)_{0}\right)$ during ablation is obtained from ClausiusClapeyron equation at the normal evaporation temperature [5]. Conservation equations of energy are: 
Energy for electrons and excited states of neutrals:

Energy for heavy-body particles:

$$
\begin{aligned}
\frac{\mathrm{d}}{\mathrm{dt}}\left\{\left[\mathrm{N}_{\mathrm{e}}\left(3 / 2 \mathrm{kT}_{\mathrm{e}}+\varepsilon_{\mathrm{I}}\right)+\mathrm{N}^{*} \mathrm{E}_{\mathrm{ion}}\right] \mathrm{H}\right\}= & \left(\mathrm{N}_{\mathrm{e}}\right)_{\mathrm{o}}\left(3 / 2 \mathrm{kT} \mathrm{T}_{\mathrm{s}}+\varepsilon_{\mathrm{I}}\right)+\left(\mathrm{N}^{*}\right)_{0} \mathrm{E}_{\text {ion }} \\
& +\mathrm{HI}_{\mathrm{ab}}-3 / 2 \mathrm{k}\left(\mathrm{T}_{\mathrm{e}}-\mathrm{T}_{\mathrm{h}}\right) \frac{\mathrm{N}_{\mathrm{e}}}{\tau_{\mathrm{e}}} \mathrm{H}
\end{aligned}
$$

$$
\frac{d}{d t}\left(N_{T} 3 / 2 k T_{h} H\right)=\left(N_{T}\right)_{0} 3 / 2 k T_{s}+3 / 2 k\left(T_{e}-T_{h}\right) \frac{N_{e}}{\tau_{e}} H
$$

where $\varepsilon_{\mathrm{I}}$ is the ionization potential of ground states of neutrals, $\mathrm{T}_{\mathrm{S}}$ is taken as the evaporation temperature, $N_{T}=\left(N_{e}+N_{0}+N^{*}\right)$, and $\left(N_{T}\right)_{0}=\left[\left(N_{e}\right)_{0}+\left(N_{0}\right)_{0}+\left(N^{*}\right)_{0}\right]$. Substituting eqs. $(10,11,12)$ into eqs. $(13,14)$, we get the rate equations for $T_{e}$ and $T_{h}$ :

$$
\begin{aligned}
\frac{d}{d t}\left[T_{e}\right]= & \sigma \frac{I_{a b}}{h v} \frac{N^{*}}{N_{e}}\left(\frac{h v+E_{e x}-\varepsilon_{I}}{3 / 2 k}-T_{e}\right)+\frac{2}{3 k N_{e}}\left(K_{e-i}-K_{i-e}\right)\left(E_{i o n}-\varepsilon_{I}-3 / 2 k T_{e}\right) \\
& -\frac{2 E_{i o n}}{3 k N_{e}}\left(K_{e-g}-K_{g-e}\right)-\frac{T_{e}-T_{h}}{\tau_{e}}+\frac{2}{3 k N_{e}}\left(\alpha_{e-a}+\alpha_{e-i}\right) I+\frac{\left(N_{e}\right)_{o}\left(T_{s}-T_{h}\right)}{H N_{e}} \\
\frac{d}{d t}\left[T_{h}\right]= & \frac{T_{e}-T_{h}}{\tau_{e}} \frac{N_{e}}{H N_{T}}+\frac{\left(N_{T}\right)_{0}\left(T_{s}-T_{h}\right)}{H N_{T}}
\end{aligned}
$$

These 0-Dimensional rate equations, i.e., eqs. $(10,11,12,15,16)$, are then solved for the five quantities of interest using second-order predictor-corrector algorithm. The starting conditions for initial distribution of particle densities in the vapor are determined by Saha equation for $\mathrm{N}_{\mathrm{o}}$ and $\mathrm{N}_{\mathrm{e}}$, and Boltzmann distribution for $\mathrm{N}^{*}$ and $\mathrm{N}_{\mathrm{o}}$, i.e.,

Saha equation: $\quad \frac{\left(\mathrm{N}_{\mathrm{e}}\right)^{2}}{\mathrm{~N}_{\mathrm{o}}}=2\left(\frac{2 \pi \mathrm{m}_{\mathrm{e}} k \mathrm{~T}_{\mathrm{h}}}{\mathrm{h}^{2}}\right)^{3 / 2} \frac{\mathrm{g}_{+}}{\mathrm{g}_{\mathrm{o}}} \exp \left(-\varepsilon_{\mathrm{I}} / \mathrm{kT} \mathrm{T}_{\mathrm{h}}\right)$

Boltzmann: $\quad \frac{\mathrm{N}^{*}}{\mathrm{~N}_{\mathrm{o}}}=\frac{\mathrm{g}_{+}}{\mathrm{g}_{\mathrm{o}}} \exp \left(-\mathrm{E}_{\mathrm{ion}} / \mathrm{kT}_{\mathrm{h}}\right)$

where $\mathrm{g}_{+}$and $\mathrm{g}_{-}$are partition function coefficients (both are equal to $6 / 15$ for $\mathrm{Si}$ ).

\section{Results and discussion}

We used a 1-D thermal model (LASER8) [6-9] to calculate the time for a solid to be evaporated under laser irradiation $\left(\tau_{\mathrm{vap}}\right)$ and the kinetic model described here for the time for vapor to be fully ionized $\left(\tau_{\mathrm{VB}}\right)$. Then, the total breakdown time, $\tau_{\mathrm{TB}}$, is given by: $\tau_{\mathrm{TB}}=\tau_{\mathrm{Vap}}+\tau_{\mathrm{VB}}$. A KrF laser pulse of FWHM $=40.0 \mathrm{~ns}$ is used for both models (as seen in Fig.1b). The total breakdown times at two laser energy fluences are calculated.

(1) Laser energy fluence $=6.0 \mathrm{~J} / \mathrm{cm}^{2}$

$\tau_{\mathrm{vap}}=22.0 \mathrm{~ns}$ (from the thermal model), $\tau_{\mathrm{VB}}=48.0 \mathrm{~ns} \quad$ (from the kinetic model)

$\tau_{\mathrm{TB}}=\tau_{\mathrm{vap}}+\tau_{\mathrm{VB}}=22.0+48.0=70.0 \mathrm{~ns}>>\tau_{\text {pulse }}$

(2) Laser energy fluence $=20.0 \mathrm{~J} / \mathrm{cm}^{2}, \tau_{\mathrm{vap}}=6.0 \mathrm{~ns}, \tau_{\mathrm{VB}}=18.0 \mathrm{~ns}$

$\tau_{\mathrm{TB}}=\tau_{\mathrm{vap}}+\tau_{\mathrm{VB}}=6.0+18.0=24.0 \mathrm{~ns}<\tau_{\text {pulse }}$

The results indicated that at an energy fluence of $6.0 \mathrm{~J} / \mathrm{cm}^{2}$ the total breakdown surprisingly occurred toward the end of the laser pulse at 70.0 ns. In this case, one may not see the vapor 
breakdown visibly by means of light emission. On the other hand, at an energy fluence of $20.0 \mathrm{~J} / \mathrm{cm}^{2}$, one may readily see the breakdown in the time frame (the total breakdown time $\sim 24.0 \mathrm{~ns}$ ) of the laser pulse duration. This is qualitatively consistent with experimental observations.

Particle density as a function of time in the plume

(Energy fluence $=6.0 \mathrm{~J} / \mathrm{cm}^{2}$ )

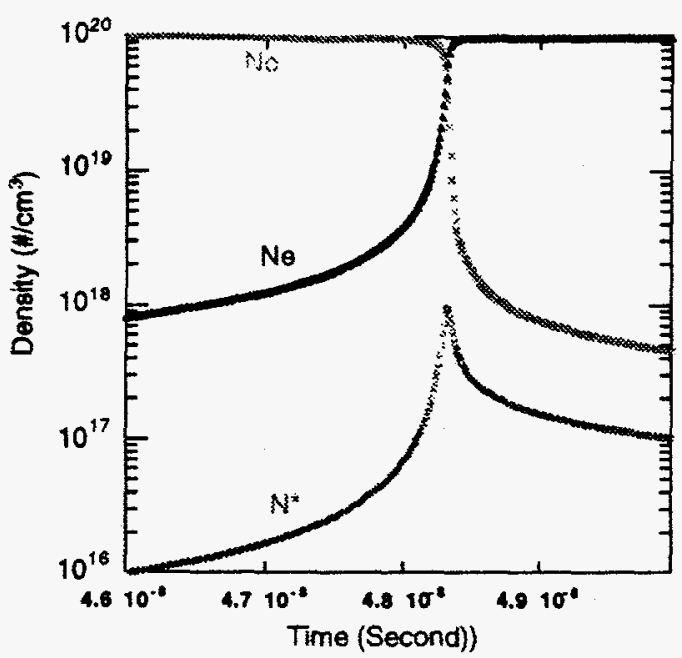

Particle density as a function of time in the plume (Energy fluence $=30.0 \mathrm{~J} / \mathrm{cm}^{2}$ )

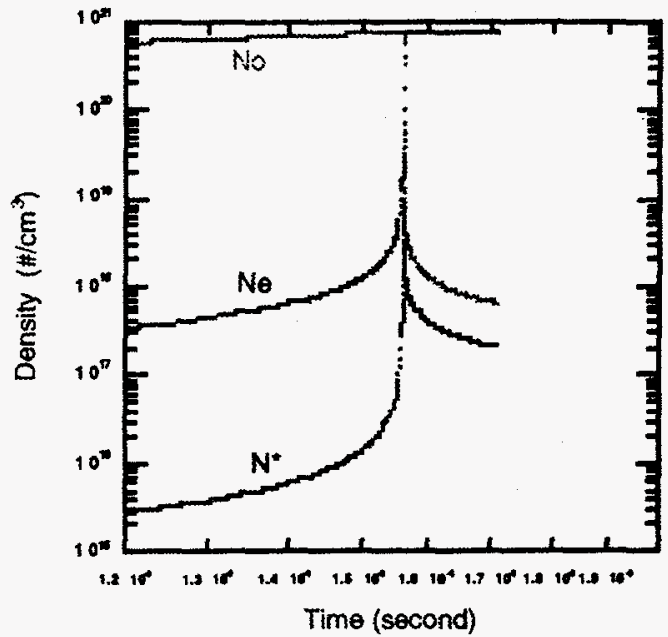

Fig.3 Particle density as a function of time from calculations, indicating vapor breakdown timings during ablation of a Si target by $\mathrm{KrF}$ laser pulses.

\section{ACKNOWLEDGMENTS}

This research was sponsored by the Division of Materials Sciences, U.S. Department of Energy under Contract No. DE-AC05-840R21400 with Martin Marietta Energy Systems, Inc., and in part by an appointment to the Oak Ridge National Laboratory Postdoctoral Research Associates Program administered jointly by the Oak Ridge National Laboratory and the Oak Ridge Institute for Science and Education.

\section{REFERENCES}

1. Ya. B. Zel'dovich and Yu. P. Raizer, Physics of Shock Waves and High-Temperature Hydrodynamic Phenomena, Academic Press, New York and London, 1966.

2. C. L. Liu, J. N. Leboeuf, R. F. Wood, D. B. Geohegan, J. M. Donato, K. R. Chen, and A. A. Puretzky, to be published.

3. D. I. Rosen, J. Mitteldorf, G. Kothandaraman, A. N. Pirri, and E. R. Pugh, J. Appl. Phys. 53,3190 (1982).

4. Andre Anders, A formulary for plasma physics, Akademie-Verlag Berlin (1990), p.159.

5. A. Vertes, P. Juhasz, M. D. Wolf, and R. Gijbels, Scanning Microscopy 2, 1853, 1988.

6. R. F. Wood and G. A. Geist, Phys. Rev. Lett. 57, 873 (1986).

7. R. F. Wood and G. A. Geist, Phys. Rev. B 34, 2606 (1986).

8. C. L. Liu, J. N. Leboeuf, R. F. Wood, D. B. Geohegan, J. M. Donato, K. R. Chen, and A. A. Puretzky, Proceedings of the International Conference on Processing and Advanced Applications of Lasers (ICPAAL), Palm Coast, Florida, May 1-6, 1994.

9. C. L. Liu, J. N. Leboeuf, R. F. Wood, D. B. Geohegan, J. M. Donato, K. R. Chen, and A. A. Puretzky, Mater. Res. Soc. Symp. Proc., Symposium A: Beam-Solid Interactions for Materials Synthesis and Characterization, Nov.28 -Dec.2, 1994, Boston, MA. 